\title{
Tratamento da orchite aguda blenorrhagica pelas injecções intra-epididymarias de electrargol estovainisado.
}

\author{
DR. O. CINTRA GORDINHO \\ E \\ DOUTORANDO W. BARNSLEY PESSÔA
}

A orchi-epididymite blenorrhagica, complicação frequente da blenorrhagia aguda em nosso meio, caracterisa-se especialmente por dois symptomas fundamentaes: a dôr e a tumefacção do epididymo com repercussão ao testiculo. Entre todos os meios therapeuticos que empregamos para combater essa affecção pertinaz afigurou-se-nos processo de grande efficiencia, de resultados mais rapidos, trazendo portanto allivio quasi immediato ao paciente, as injecções de electrargol, cuja acção sedativa se manifesta rapidamente ao fim de algumas horas. As' vantagens do methodo seriam enormes se não fossem os phenomenos dolorosos que se succedem logo alpós á injecção, prejudicando seriamente a vóga do tratamento, determinando a repulsa dos doentes pusillanimes em acceitarem um segundo tratamento em caso de nova indicação.

Foi justamente para obviar a estes incovenientes que imaginámos uma modificação da technica até então empregada, technica esta que se encontra descripta e commentada nos annaes da Casa Clin de Paris

Primeiramente empregámos injecções de electrargol ( 2 a 5 c. c. ) intra-epiddilymarias seguidas de uma injecção sub-cutanea de clorhydrato de morphina. Não obstante esse hypnotico a dôr immediata era violenta. Apezar dos bons resultados verificados, pois a dôr cedia em algumas horas e o epididymo voltava ás suas dimensões primitivas em menor lapso de tempo, ainda não possuiamos o methodo ideal. Para que essa therapeutica entrasse na pratica corrente era mistér que, além de sua simplicidade e efficacia, não fosse dolorosa, pois a dôr acovarda sempre! Proseguindo em nossas experimentações, crêmos ter chegado a um methodo talvez ainda não perfeito, porém qu€ nos tem dado resultados plenamente satisfactorios nos numerosos casos em que o empregámos em nossa clinica hospitalar e civil. Con siste o methodo (Dr. C. Gordinho) em injectar uma solucção de 2 c. c. de electrargol e estovaina a $10 \%$ em partes eguaes simulta neamente no epididymo e no tecido cellular sub-cutaneo adjacent ao cordão espermatico. A picada é a unica parte dolorosa do trata mento. (sic). Torna-se o epididymo, sob a acção da estovaina, inser 
sivel e decorrido um periodo de tempo variavel, (2-3 horas) recobra gradativamente sua sensibilidade primitiva para então desapparec completamente entre 10 e 15 horas, segundo os casos observados.

O electrargol estovainisado, solbre ser eminentemente sedativo, - actúa sobre o processo inflammatorio, diminuindo-o e apressando a sua resolução.

\section{TECHNICA DA INJECÇÃO}

$\mathrm{Na}$ orchi-epididymite blenorrhagica o processo inflammatorio, como dissémos, se assesta de preferencia no epididymo, augmentando-lhe extraordinariamente o volume e fazendo-o attingir de ordinario de 20 a 30 vezes o seu tamanho primitivo. Dada esta condição e o conhecimento exacto da sua posição anatomica, facil é encontral-o. A injecção deve ser praticada com todo o rigor da asepsia. Si houver anteriormente pomadas no escroto, retiral-as com alcool, benzina. etc. Para maior facilidade didactica descrevemol-a em tempos.

1. Asepsia rigorosa da região com tintura de iodo a $10 \%$.

2. Preparar a solução de electrargol e estovaina a $10 \%$; 2 a 5 c. c. em partes eguaes.

3. Injectar no trajecto do cordão espermatico de 1 a 3 c. c. da solução acima.

4.' Injectar lentamente "in loco dolente" do epididymo de 1 a 2 c. c. da mesma solução.

5. Auxiliar pelos meios habituaes de tratamento como sejam: bolsa de gelo, de agua quente, pomadas de base de collargol, etc.

\section{OBSERV AÇõES}

Damos á publicidade algumas das nossas mais interessantes obse"vações, em que se pode verificar ao lado da effficacia do tratamento o seu valor pratico, permittindo aos doentes a volta quasi immediata ás suas occupações habituaes, ao contrario de seus congeneres que exigem delles um repouso de, pelo menos, 10 a 15 dias.

I - J. A. 20 annos. (obs. W. Pessôa).

Entrou para a II H. C. amparado por um enfermeiro; facies pallida, crispada pela dôr.

Verificámos tratar-se de uma orchite aguda blenorrhagica esquerda, datando de 5 dias. Epididymo muito augmentado e extremamente doloroso. Praticámos uma 
injercão de 0.8 c. c. de electrargol com egual quantidade de estovaina. Injeç̧ão de egual quantidade de electragol estovainisado sobre o trajecto do coridão espermatico. Nâo collocámos bolsa de gelo nem empregámos quaesquer outros meios therapeuticos.

Manhã seguinte: Epididymo de volume menor, indolor. supportando perfeitamente a palpação.

Alta dois dias depois. Não sentia doress, o epididymo porém, ainda não havia regredido ao seu volume primitivo.

II - M. A. 22 annos. II C. H. (obs. W B. Pessôa).

Orchi-epididymite aguda blenorrhagica esquerda, datando de 6 dias. Praticámos pela manhã uma injecção de 0,5 c. c. de électrargol estovainisado. INão empregámos. outros metholdos therapeuticos. Na manhã seguinte chamamos a attenção de varios collegas para o. epididymo do paciente que havia diminuido quasi da metade e a apalpação era completamente indolor. O doente sentiu tal allivio que nos pediu outra injecção. Alta quatro dias após.

Epididymo quasi normal e indolor. Foi um dos resultados mais rapidos que obtivemos.

III - V. B. 19 annos (obs. W B. Pessôa).

Orchi-epididymite blenorrhagica. Recidiva pela terceira vez. Epididymo tumefacto e muito doloroso. A. noite praticámos uma injecção de 1 c. c. de electrargol estovainisado. Manhã seguinte: Epididymo sómente doloroso á presião. Neste caso prescrevemos pomada de collargol e bolsa de agua quente. Demos alta só no fim de 10 dias de repouso para evitar futuras recidivas.

IV - (Obs. Dr. C. Gordinho)

V. A. Vindo do interior. procurou-nos para que tratassemos de sua orchite.

Epididymo enorme e extremamente doloroso. O doente ine exacerbavem difficuldade devido aos movimentos que ihe exacerbavam a dor. Fizemos-lhe no escriptorio uma injecção de electrargol estovainisado (1 c. c.) no epididymo affectado, que o doente supportou sem a menor
reacção dolorosa.

Repouso, bolsa de gelo, Uraseptina. 
Dia seguinte - Testiculo não doloroso á pressão, sómente o cordão espermatico era ainda um tanto sensivel.

Adenite urethral formando-se na urethra anterior. Nesse mesmo dia o doente foi ao consultorio a pé onde operamos-lhe a adenite urethral. O testiculo não mais o incommodava, mostrando-se completamente indolor. Esta observação é recentissima achando-se ainda $o$ doente em tratamento de sua blenorrhagia.

V - (Obs. Dr. C. Gordinho).

S. P. vem sofffrendo ha oito mezes de orchite blenorrhargica recidivante. A menor mudança de regimen produz-lhe recahida da molestia. Ha mais de quatro mezes que é obrigado a guardar o leito. Consultára varios especialistas, tendo um delles declarado, segundo palavras textuaes do doente, "que se habituasse com a enfermidade, pois se tratava de um molestia incuravel"

S. P. para dar algum lenitivo lás suas dores, fazia uso diario de pantopon. Foi neste estado que vimos o doente pela primeira vez. Propuzemos-lhe a therapeutica radical, a injecção de electrargol, que foi acceita pelo nosso doente que se achava: atacado de uma neurasthenia sexual profunda. Pelo toque verificámos uma prostata congestionada e vesiculite esquerda. Praticámos no dia immediato a injecção de electrargol no epididymo affectado. Bolsa de gelo, pomada e supositorio de base de collargol.

No dia seguinte o quadro da molestia se modificára por completo. O epididymo, comquanto augmentado de volume, não era doloro'so á pressão, não incommoldava mais o doente, que tambem se nos apresentou moralmente transformado. As melhoras se accentuaram rapidamente, permittindo-nos dois dias após verificar por meio de uma sonda a existencia de um estreitamento urethral firiforme.

Praticámos a urethrotomia interna cinco dias depois da injecção de electrargol. Sonda de demora por 48 horas.

Dilatação progressiva cada dois dias, seguida de instillações de argyrol Barnes a $5 \%$. Em 10 dias o nosso doente, sentiu-se apto para deixar o leito, passeiando, sem sentir o menor incommodo para o lado do testiculo. Ao 
cabo de 15 dias de traiamento obteve alta, continuando naturalmente as dilatações e instillações.

Hoje, isto é, anno e meio após a injecção de electrargol, ainda não se manifestou o menor symptoma para o lado do testiculo que o obrigára a guardar o leito por quatro mezes.

Esta observaçāo por si só vale para a consagração de um methodo.

São Paulo. 30 de Abril de 1921.

\title{
Sobre um cáso de distomatose produzida pelo clonorchis sinensis
}

\author{
PELO DOUTORANDO \\ CARLOS NAPOLEÃO LATERZA
}

(Communicação feita á Sociedade de Medicina e Cirurgia de S. Paulo.)

ANAMNESE - Trata-se de um japonez. K. T., com trinta annos de irlade. casado, trabalhador, residente no Brasil ha cinco annos.

Entrou para a Segunda Enfermaria de Medicina de Homens, z cargo do prof. Dr. Rubião Meira, a 14 de outubro de 1919.

Trata-se de um homem de estatura pequena, porém, de constituição robusta.

Recolheu-se ao Hospital da Santa Casa, porque estava muito edemaciado e com muita fraqueza, vendo-se assim impossibilitado de trabalhar

INTERROGATORIO - ANTECEDENTES HEREDITARIOS Pae. fallecido de dysenteria. Mãe, fallecida de senilidadle. Irmãos : quatro ao todo, sadios.

ANTECEDENTES PESSOAES - Não se lembra de ter tido molestias peculiares á infancia Nega molestias venero-syphiliticas.

HISTORIA ANTERIOR DA MOLESTIA - Em janeiro de 1918 ficou com o corpo todo edemaciado (anasarca); chamou o medico que, com tratamento adequado, conseguiu cural-o, sendo que em agosto estara completamente restabelecido. Diz o doente que o diagnostico que o medico fez foi de nephrite. Actualmente repetiu-se a mesma molestia, que se inicion com edema dos membros inferiores. generalisando-se por todo o corpo. Impossibilitado de trabalhar viu-se na contingencia de se recolher ao Hospital para o seu tratamento.

SYMPTOMATOLOGIA - Lamenta-se o doente de muita fraqueza. cephaléa e dores d ffusas pelo corpo. Apresenta-se edemaciado, com anasarca, isto é. com edema dos membros inferiores. abdomen. membros superiores. thorax. faces e palpebras. 
Tem ganglios epithrocleanos.

Retumbancia da segunda bulha no fôco aortico.

EXAME DE LABORATORIO - Reacção de Wassermann $(+++)$ Bem positiva.

EXAME DE FEZES - Caractéres urganolepticos: - Pastosas, côr de café, cheiro fecaloide.

Exame microscopico. - Revelou raros ovos de Clonorchis sinensis.

ANALYSE DE URINA - Verificou-se uma forte olyguria pela colheita de urina durante vinte e quatro horas.

Albumina - Grande quantidade (20 grs. por mil).

Assucar - Após decantação pelo liquido de Courtone reduziu fortemente o licor de Fehling e o reactivo de Nyländern, haviendo portanto, no caso, notavel quantidade de glycose, que não foi dosada.

Sedimento - Cellulas epitheliaes - algumas.

Hematias - raras.

Leucocytos - raros.

Cylindros - numerosos, granulosos

Crystaes - não ha.

N. B. A anamnese do doente foi muito difficil por elle não conhecer o nosso idioma.

\section{IMPORTANCIA DA PRESENTE COMMUNICAÇÃO}

- O ponto capital da questão é o facto de parecer que é o primeiro caso a assignalar no Brasil e não sei bem se na America do Sul.

Por uma carta que escrevi ao Sr. Dr. Adolpho Lutz, de Manguinhos, obtive uma resposta na qual o illustre parasitologista diz o seguinte: - "O Clonorchis é um parasita apparentemente commum em certas regiões, e frequente entre japonezes emigrados, como foi identificado em Cuba e na America do Norte" Parece, pois, que ainda não foi verificado na America do Sul.

$\mathrm{E}$ tambem de importancia o seu conhecimento, agora que a immigração japoneza está se intensificando para a America do Sul. E já não é n primeiro caso que os japonezes têm exportado porque o professor Dr. A. Carini teve occasião de encontrar no escarro de um japonez os ovos de Paragonimus Westermanni.

Em se tratando de um assumpto muito pouco conhecido entre nós procurei fazer um eschema do estudo completo que até hoje tem sido publicado.

HISTORICO - Origem do termo - $\beta \dot{\lambda} \omega \nu$, Kĩuvós (ramos) + òoxis (testiculos) isto é, testiculos ramificados.

Descoberto em 1874 quasi que simultaneamente por Mac Connell e Mac. Crregory, foi descripto em 1875 por Cobbold com o nome de Distomum sinensis.

Em 1883, Baelz, que ignorava os trabalhos dos medicos inglezes. fez. na mesma época descripções importantes no Japão e acreditou ter encontrado duas novas especies que denominou: Distoma hepatis endemicum, sive, perniciosum e Distoma hepatis inocuum.

W. Taylor, Isao Ijiana e R. Blanchard recunheceram a identidade do parasita descripto por Cobbold e daquelles encontrados por Paelz.

Eim 1895, R. Blanchard incluiu o Distoma chinez no genero Opis= 
torchis, que elle estabelecia para os distomas cujos testiculos se acham atraz do ovario.

Em 1907 Loos collocou-o no genero Clonorchis, creado para os trematoides cujos testiculos atraz do ovario sāo ramificados, reservando o nome de Opistorchis para aquelles cujos testiculos são lobados.

Recentemente Verdun e Bruyant distinguiram duas variedades de Clonorchis Sinensis: uma variedade Major, na qual o verme adulto tem treze a dezenove millimetros die comprimento sobre tres a quatro millimetros sobre 2 millimetros de largura, e cujos ovos teriam 26 parasita, que corresponderia ao Distomum hepatis innocuum de Baelz. frequente na China, seria raro no Japão.

A variedade Minor, em que o verme tem um comprimento de 10 a13 milimetros sobre 2 milimetros de largura, e cujos ovos teriam 26 micra por 15 micra, referir-se-ia ao Distoma hepatis endemicum, sive; perniciosum de Baelz. Esta veriedade seria muito commum no Jopão, em Tonkin e em Annam.

Mathis e Leger pelos seus estudos feitos em Tonkin em. 1911 acham que não é possivel uma distinç̧ão entre duas variedades, baseada somente sobre as dimensões. Pelas medidas feitas vierificaram, medindo um grande numero de parasitas adultos, como dimensões extremas 12.5 e $20 \mathrm{~mm}$. de comprimento e 2 a $3,2 \mathrm{~mm}$. de largura.

SYNONIMIA - Distomum sinensis, Cobbold, 1875; D. spathulatum, Leuckart, 1876; Distomum hepatis innocuum, e Distomum hepatis en= demicum, sive, perniciosum, Baelz, 1883; Opistorchis sinensis, Blanchard, 1895; Clonorchis sinensis, Loos, 1907.

HABITAT - Nos canaliculos biliares do homem; nos canaliculos biliares do cão e do gato.

DISTRIBUIÇÃO GEOGRAPHICA - China, Japão, Annam e India.

DESCRIPÇẢO DO VERME-E' um plathelmitho, trematoide, distomideo ou fasciolideo do genero Clunorchis, tendo o corpo não segmentado, foliaceo, provido de um tubo digestivo sem anus e de duas ven-
tosas.

Corpo achatado, de côr avermelhada, com a parte anterior estreitada, apresentando duas ventosas, uma oral, outra ventral, approximadas, tendo ramos intestinaes longos e simples que vão até á extremidade posterior do corpo; - póro genital logo adiante da ventosa ventral; testiculos ramificados, collocados atraz do utero; i : utero contem numerosos laços com innumeros ovos pequenos; póro excretor terminal.

VARIEDADES - Verdun e Bruyant (1908) descrevem duas variedades de Clonorchis sinensis: - o C. S. major e o C. S. minor. De seus estudos recentes, C. Math is e M. Leger (1911) concluiram que não ha razão de ser para duas variedades de Clonorchis, baseada essa distincção somenlte subre a's dimenisões, conforme Bruyant e Verdun querem; e tendo medido um certo numero de exemplares adultos, encomprimento sobre $2 \mathrm{~mm}$. a $3,2 \mathrm{~mm}$. de largura.

Verdun e Bruyant dão para a variedade major 13 a $20 \times 3$ a $4 \mathrm{~mm}$. e para a variedade minor 10 a 13 × a $3 \mathrm{~mm}$.

Os ovos são pequenos, ovoides, de côr amarellada, apresentando numa extremidade um operculo e na outra uma pequena ponta em largura.

EVOLUÇÃO - E' desconhecida. 
Pela girande analogia que apresenta com o distoma do figaldo, da Europa, a Fascicola hapatica, e com o pequeno distoma, o Dicrocoelium lanceatum, acredita-se que é no estado de cercarias que os distómas chinezes plenetram no tubo digestivo do homem.

Si as cercarias estão livres na agua, ellas são absorvidas directamente: si estão encystadas, quer sobre uma planta aquatica, quer no tecido de um mollusco ou de um peixe, a infestação deve fazer-se por intermedio desses elementos consummados crús ou cosildos insufficientemente.

INFESTACÃO E PROPHYLAXIA - Dada a incerteza que se tem sobre a infestação tambem mais incerta é a prophylaxia, visto que esta depende incontestavelmente daquella.

Billet incrimina um mollusco de genero Melania ou talvez Palu= dina Laosensis no qual encontrou esporocytos.

Segundo Kastsurada, o homem se infestaria, quer comendo certos peixes, quer directamente, sem hospede intermediario, bebendo agua polluida ou ingerindo plantas aquaticas que conteriam cercarias encystadas.

Kobayaski provou a sua hypothese, pois conseguiu infestar experimentalmente gatos, coelhos e cobayas com cystos encerrados em musculos de diversos peixes de agua doce da provincia de Okayama. principalmente Pseudorasbora e Leucogobia Güntheri.

Fraisisinet indica que segundo Lutz a Limnea Peregrata sierila o hospede de escolha. Os indigenas fariam grande consumo deste mollusco que figuraria em todos os mercados e que seria denominado "côn hop"

Mathis e Leger verificaram que nenhum tem esse nome e que a Liminea Peregrata não entra na alimentação dos anamitas. Acham que Fraissinet confundiu "côn hop" com "con ôc" que é o termo generico, com que os indigenas de Tonkin chamam todos os mariscos aquaticos.

Em resumo, o desenvolvimento genetico do Clonorchis sinensis é até agora hypothetico.

MODO DE FIXAÇÃO - A sua fixação é feita pela applicação das ventosas ás paredes dos canaes biliares. Alimentam-se de bile e de sangue.

PATHOLOGENIA - Os distomas em geral exercem sobre o organismo. - a) uma acção espoliadora: b) uma acção mechanica; c) uma acção irritativa: d) uma acção toxica ou talvez bacterifera.

A) - Acção Espoliadora - Os coecuns intestinaes de um Distoma encerram uma massa escura que sahe á pressão e que muitos auctores consideram como bile. - Raillet provou que se alimentam de sangue.

A perda de sangue é relativamente pequena, entretanto, prolongando-se, póde acarretar enfraquecimento urganico.

B) - Acção Mecanica - Quando são numerosos obstruem os canales biliares e mesmo os pancreat cos. Podem, assimi produzir uma ictericia de retenção mais o menos pronunciada. Podem comprimir certos pontos do systema venoso porta, dando origem á ascite éa hypertrophia lienal.

C) - Acção Irritativa - Vide anatomia pathologica.

D) - Acção Toxica e Bacterifera - As lesões hepaticas são muito pouco importantes, comparando-as $\mathrm{cm}$ as que produziria um cysto hydatico volumoso, frequentemente bem tolerado pelo organismo, graças á grande plasticidade do figado. 
Lim muitos casos, entretanto, a distomatose hepatica é grave, gravidade essa ligada provavelmente ás substancias toxicas lançadas pelos distomas na corrente circulatoria.

A cachexia aquosa produzida pela Fasciola hepatica e pelo Dicroelium lenceatum em certos animaes, é, comtudo, comparavel, a té certo ponto, com a anemia verminosa produzida pelo Dibotriocephalus latus on pelo Trichocephalus trichiurus.

E' admissivel que na migração dos Distomas do intestino para o figado ou para os canaes pancreaticos transportem microbios intestinaes capazes de produzir angiocholite, pancreatite, podendo mesmo inoculal-os pela picada no apparelho circulatorio.

ANATOMIA PATHOLOGICA - As lesões determinadas pelos Distomas foram descriptas por Grall, Vallot, Moty, Katsurada, Blanchard, Gaide.

Macroscopicamente se caracterizam pela congestão e hypertrophia do figado, pela dilatação dos canaes biliares obstruidos pelos Distomas.

Histologicamente se nota o espessamento das paredes dos canaes bịliares, alterações do epithelio e o apparecimento de canaliculos de neoformação. A proliferação do tecido conjunctivo_não se limita ás paredes das rias biliares; ella pode se estender a todo o parenchyma hapatico. Finalmente o processo termina em uma verdadeira cirrhose e os elementos nolires soffrem a degenerescencia graxa ou granulosa.

Anatole Leger occupou-se recentemente, re novo, do estudo anatomo-pathologico do figado parasitado pelo Clonorchis sinensis. Notou particularmente a reacção dos canaes biliares infestados, sob a forma de produç̧ão adenomatosas ou papillomatosas, ás vezes polycysticas. verdadeiras neoplasias benignas provocadas pelos parasitas. Elle approxima estes phenomenos reaccionarios daquelles provocados, p. e x.. pelos de Bilharzias no recto e na bexiga.

Sabrazés e Leger notaram uma eosinophilia local de graú elevado nos figados parasitados. Esta reacção eosinophilica, constituida pelo apparecimento de varias cellulas acidophilas, uninucleadas ou polynucleadas. é de qualquer modo a resposta dos tecidos parasitados ás acçōes toxicas produzidas pelo trematode. Ella é approximada daquella assignalada, em 1903, por Sabrazés no tecido conjunctivo que envolve os cystos hydaticos.

Estas alterações avançardas permittem comprehendt $r$ o syndromo da insufficiencia hepatica observada em certos casos: - perturbaçóes da digestão e da absorpção, em seguida á parada da bile; perturbações urinarias; ascite, por compressão no figado dos ramos de divisão da veia porta; perturbações nervosas de ordem reflexa, por irritação mecanica.

Emfim pode-se suppôr que o Distoma actua tambem por'secreçôes toxicas e talvez directamente nos capillares dos canaes, semelhantemente ao facto que mencionou Raillet para a Fasciola hepatica.

SYMPTOMATOLOGIA - Quaes os symptomas determinados pelos parasitas alojados nos canaes biliares?

E' impossivel affirmar com precisão. Com effeito, não se cunhece syndrome proprio da distomatose hepatica.

Gaide resume assim o quadro clinico observado em certos casos de infestação: - "congestão do figado com hypertrophia notavel, ictericia mais ou menos accentuada sem descoramento das fezes, perturbaçõos digestivas e perturbações urinarias consecutivas, febre de typo 
irregular, bradycardia e perturbações nervosas de ordem reflexa com alguma tendencia ao coma e á hypothermia".

Sambúc relata um caso, longamente estudado, de distomatose em que foi necessario a cholecystectomia. Os symptomas apresentados lembravam os da hepatite suppurada e da lithiase biliar: dôres hepaticas lancinantes fazendo pensar nas dôres de calculose, escapulalgia, hypertrophia consideravel do orgão, febre intensa, vomitos biliosos abundantes. As puncções do figado só tendo dado bile, foi estabelecido o diagnostico de angiocholite com cholecystite. No decorrer da operação verificou-se a sahida de numerosos distomas.

Notamos na observação de Sambúc a erupção de urticaria muito forte e tenaz, sob́revinda após as puncções, e que era, em todos os pontos, identica ás erupções que succedem ás puncções do cysto hydatico do figado.

Quando o figado é parasitado por numerosos Distomas (avaliou Blanchard em mais de dez mil o numero de parasitas que encerrariam os canaliculos biliares do figo de um anaumita vindo dos hospitaes de Hanoi), pode dahi resultar uma insufficiencia hepatica.

Nos casos extremos. Taylor assignalou, no periodo terminal da anasarca. uma diarrhéa difficil de dominar. finalmente cachexia, um enfraquecimento progressivo e a morte.

Billet, em Caobang, em 1893, attribuiu á distomatose a morte subita de um anamita que se pensava ter sido assasinado. Os canaliculos de vesicula biliar estavam distendidos e continham numerosos Clo= norchis sinensis. O tecido hepatico apresentava-se fortemente esclerosado, havendo, além disso, pleur.sia e pericardie purulentrals.

Mas, nos casos em que a infestação é ligeira, ella passa absolutamente despercebida, e só o exame repetido das fezes permitte saber que o figado está parasitado.

Grall crê que os medicos do Japão têm sobrecarregado o quadro clinico da molestia. Para elle o Distoma chinez apenas determina um estado doentio, e a morte, quando sobrevem deve ser attribuida a uma infestação intercurrente.

Mathis e Leger, em 1906, tiveram a idéa de pesquisar a insufficiencia hepatica pela prova do azul de methyleno. Foi verificada, nos portadores de Distoma, uma diminuição da duração total da eliminação, um retardamento no apparecimento do maximo da intensidade de eliminação, e intermittencias precoce no curso de eliminação. Este rythmo polycylico em particular é o que se observa nos ictericos chronicos e no figado cardiaco em gratu adiantado.

A formula leucocytaria. estabelecida em trinta e quatro indigenas portadores de Distomas. só ou com associação de outros helminthos. nada têm de caracteristica. O augmento da taxa de acidophilos, nos casos difficeis, serve de elemento de diagnostico differencial cóm a hepatite suppurada. sendo que nesta se encontra hypo-eosinophilia.

DIAGNOSTICO -.. O diagnostico é quasi impossivel de se fazer. sobretudo nos paizes em que grassa o impaludismo. O exame de fezes: é o unico meio que pode descobrir a origem das pertubaçōes hepat:cas nesses casos, como no caso presente em que, favorecido pelo acaso encontrei o Distoma, porque geralmente a presença de um pequeno numero desse parasita no figado, passa despercebida e a sua presenca só é revelada pelo exame das fezes ou pela necroscopia.

N. B. - Este diagnostico foi confirmado pelo Professor Dr. Celestino Bourroul, lente de Parasitologia da Faculdade de Medicina e Cirurgia de S. Paulo. 
PROGNOSTICO - A infestação intensa pelo Clonorchis sinensis é uma das mais graves molestias parasitarias - nos paizes em que se encontra - visto a impossibilidade de agir sobre os trematodes.

Quando os parasitas são em pequeno numero, o portador pode viver por longo tempo.

E' de notar a longevidade do Clonorchis, o que explica a facilidade e a possibilidade de accumulo desse parasita alojados nas vias biliares. TRATAMENTO - Foi empregado o benzoato e o salicylato de sodio, sem resultado.

Por emquanto tem sido o tratamento puramente symptomatico.

\section{Problema Vital}

Não existe talvez, no seio do corpo discente da nossa Faculdade, problema tão discutido e realização tão desejada como a do reconhecimento da Escola, que frequentamos. Não existe tamibem para Iús causa mais bem amparada pela Justiça. E' que tal aspiração se nos depara como uma necessidade e consegui-la é problema vital.

Effectivamente, as condições de meio encontradas pelos medicos å Faculdade de S. Paulo, não são das mais propicias para o exercicio de sua profissão. Vencidos os seis longos e trabalhosos annos do curso, o novo graduado tem de lutar dentro dos limites do Estado, hoje bastante pequeno para campo onde se desenvolva a actividade de tantos companheiros de officio, que o procuram para o exercicio da carreira. D'ahi a competição.

E se esta é legitima, nada tem de iniquo para os que a intentam, claro é que as desvantagens sempre existem para os que são obrigados neste terreno a enfrenta-la, sem faculdade de procurar outro ambiente, que não o marcado pelas relativamente estreitas balisas estudoaes. Fica, pois, o recem-formado cingido dentro de tal limite; e, consideralo o numero sempre crescente dos medicos graduados por outras Escolas que acorrem ao nosso Estado, principalmente extrangeiros, ver-se-á claramente que aquellas desvantagens augmentam tambem gradativamente para os novos medicos que aos pcucos vão sendo formados pela nossa Faculdade.

Poder-se-á objectar que o territorio assim marcado é vasto e sufficiente, não só agora mas no futuro, quando crescer o numero de medicos e com elle, parallelamente, o da população. Argumentos, com leve tinta de jacobinismo, procurarão demonstrar que até ha vantagem no facto dos medicos paulistas serem obrigaldos a enfrentar o elemento forasteiro nos nucleos mais habitados do Paiz, ccmo o nosso Estado. 
Não ha, porém, nenhum argumento possivel, para se encobrir a evidente injusta de se fecharem as portas do despartamento estadoal aos medicos de S. Paulo, só porque se formaram numa Faculdade, onde o ensino é identico e a situação egual ás das demais contempladas pelos favores do reconhecimento federal.

E se para os medicos paulistas as vantagens advindas desta regalia são patentes, (1) não se ponha em duvida a tempera de suaś armas para os combates dentro da aldeantada circuimscripção, em cuja Capital se formaralm. Mas, não se pode negar, tha zonas do territorio patrio onde seriam maiores, por qualquer circumstancia individual, as facilidades de vida e mais propicio o ambiente para muitos, ainda sen garantia de recursos para o proprio sustento, que necessitam infelizmente de curto prazo para estabilização nos diffice:s primeiros annos de vida prófissional.

Por isto - reatanido - o estabelecimento de uma medida que ponha fim á esta situação de desegualdade entre profissionaes da mesma classe, trabalhando no mesmo paiz, terá para nós o valor de um amparo.

E este é tão grande quanto facil: o reconhecimento da Faculdade de Medicina e Cirurgia de S. Paulo.

A facilidade, porém, para a resolução $d_{0}$ problema apresenta, em compensação, a relativa difficuldade para se conseguir aquella medida.

Fala em bem desta affirmativa o facto da nossa Faculdade contar já oito annos de vida sob a egide governamental, ter sempre funccionado regularmente e até hoje ainda não dar aos seus alumnos diplomas reconhecidos pela União.

Capricho? Não, certamente. O Governo Estadoal, en principio, não se desinteressa pela sorte da Faculdade; os seus directores tem se empenhado em conseguir o reconhecimento; e á aspiração do corpo discente casa-se o mesmo desejo da Congregação.

Ainda ha pouco, quando de sua passagem pela Directoria da Escola, o Prof. Ovidio Pires.de Campos escreveu um longo estudo fundamentan do o pedido do reconhecimento. Nesse memorial, com que demonstrou aos alumnos não ter se esquecido de sua promessa quando empossado no alto cargo, a questão foi collocada em termos precisos, e ao desejado reconhecimento tres caminhos foram abertos: por lei federal, por deliberação do Conselho Superior do Ensino e, finalmente, por um processo de reconhecimentos estadoaes parcellados.

Destes, os dois primeiros tinham portões fechados, quanto a conveniencia de serem preferidos. Senão vejamos:

(1) Ha cargos officiaes e não officiaes que exigem medicos formados em Faculdades 1 econhecidas pela l'niăo. 
A lei federal, dando como idoneos os diplomas passados pela Faculdade de S. Paulo (2), ia collocar a questão em uma assembléa onde accordaria desejos identicos de outros Estados com Escolas em condições semelhantes ás da nossa. E o resultado se deduz: seria, depois de longo debate entre representantes desejosos cada qual de servir ao seu Estado, uma lei geral de reconhecimentos, para todo o Paiz. Ora, por isto mesmo, qualquer projecto neste sentido, por influencias directas ou indirectas. teria fatalmente de soffrer encalhe, no Congresso, porque as suas consequencias e desivantagens não escanam aos espiritos bem intencionados e de vistas largas.

Por outro lado - segundo caminho - haveria o recurso do Consclho Superior do Ensino que, é certo, não opporia emibargos á pretenção. Ficaria assim a nossa Escola equiparada, ao fim de um determinado prazo, supponhamos - um anno, necessario para a fiscalisação .

E que é necessario para a equiparação? Somente o pedido, demonstrando que a Faculdade obedece aos moldes da Escola-padrão creada pelo Conselho. Isto importa em dizer que a nossa Faculdade precisa ser modificada na sua organisação basica, na seriação das suas cadeiras, em o numero destas, soffer emfim uma transformação radical - transformação que vae de encontro aos propositos̃ dos dirigentes publicos, firmes no desejo de conservar a Escola como está, porque é assim que ella tem firmado creditos, pelos seus magnificos resultados, e só assim ella poderá continuar a ser, "sem jactancia, gloria do Governo que a fundou e padrão notavel do Estado que a inantem"

Com a equiparação, portanto, perderia a Faculdade a sua autonomia porque sobre ella teria poder directo o Conselho, fiscalisando todos os seus actos de vida interna, dos mais simples aos mais complexos, com direito mesmo a julgar "de meritis"

Resta a terceira solução do caso que é, no fundo, uma synthese; na forma, uma analyse: processo de reconhecimentos estadoaes parcellados. Por elle, os diplomas da nossa Escola dariam direito aos seus passuidores de clinicarem nos Estados, em que este exercicio medico fosse franqueado por lei especial. A principio esta concessão seria outorgada por um Estado; logo depois o exemplo teria imitadores, e assim, aos poucos, o reconhecimento seria uma realização completa em todo o Brasil. Vale dizer: reconhecimentos estadoaes perfazendo, na sua equivalencia de vantagens, um reconhecimento federal.

Isto é possivel. Para comecar, é bem considerar-se que o exercicio ce uma profissão em cada Estado obedece a detər ninados preceitos rigulamentares. Por tal se explica porque no Rio Grande do Sul.

(2) Caso da Escola Polytechnica de S. Paulo. 
por exemplo, os medicos não precisam exhibir titukos de habilitaçãu. Em outros Estados, pelo contrario, aos profissionaes não basta ter diploma, é necessario ainda registra-lo.

Depois - não vae, em tal affirmativa, laivo de pretenção ou immodestia - a Faculdade de S. Paulo, pela sua organisação solida e pelo seu regimen severo, offerece garantias quanto á natureza do: seus diplomas ( 3 ). Não ha, pois, motivos em contrario para que sejam em alguma parte rejeitados como não evidenciadores da competencia de quem os apresente.

Este ultimo processo de reconhecimento será talvez menos rapido do que os outros dois. Mas apresenta, no fundo, as mesmas vantagens. Haverá razão para o esquecenmos? 'Motivos para o preferirmos?

Será difficil dize-lo, repentinamente. Tudo depende de um demorado exame, que não pode ser feito agora no mleio destas considerações ligeiras, escriptas ao correr da penna. E' necessario sempre ter-se em vista o beneficio do reconhecimento e com este confrontar os varios meios de sua realização.

A' primeira vista, avulta em excellencia o processo da equiparação, decisivo e rapido. Porém ao espitrito sereno, conservador e moderado, repugna uma transformação subita em normas bem defendidas pela experiencia. E aos de prática, tudo está a indicar, em horizonte² amplo e limpo, que melhor convem uma conservação de regimen.

Ainda ha pouco, auctoridade tambem muito acatada em materia d€ ensino, falando desta Esicola affirmava que certamente ella "nunca terá em seu passivo leis intempestivas, nem inuteis, nem theoricas. nem pessoaes. E meridianamente resahe a conclusão de que ella tem seu favor possibilidades de tal jaez, que se não encontram melhores nas existentes parcellas da federação brasileira. Seu caminho é facil, seguro, desempecado de multiplos estorvos por que têm amiude as outras de romper para a victoria definitiva. E os poucos annos de sua existencia o demonstraram brilhantemente"

Por outro lado, se quizermos o reconhecimento sem modificação do actual regimen, levando em conta a base em que se assenta a opinião supracitada, temos de appellar para o Congresso Nacional. Mas a lei que nos pode abrir caminho e alargar o circulo de acção. ex:ge, é innegavel, a circumstancia de uma opportunidade, que não a presente. Questões de politica, comprehende-se. Somente destas depende vingar o alvitre de uma lei especial para a nossa Faculdade.

Em resumo: tres caminhos. Por onde seguir?

(3) "Sāo Paulo pode orgulhar-se de sua Faculdade; ella conquistou inelutavel direito de existencia". (Prof. Oscar Freire - Licção inaugural do Curso de Deontologia Medica). 


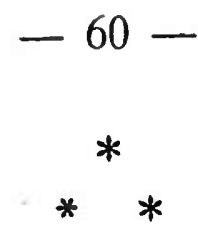

Comtudo, emquanto a situação é de escolha e de duvida, uma cundição se mostra: é a necessidade de se tornar conhecida, no Brasil, a Faculdade de S. Paulo, publicando-lhe os trabalhos, vulgarisando-os nos meios scientificos, submettendo-os ao juizo dos entendidos, para que, e só assim — o reconhecimento se imponha como obra ıde justiça.

A questão da desigualdade ainda está ide pé, na hora actual, e não se enxergam „motivos que colloquem o estabelecimento de ensino paulista em nivel inferior ao dos demais congeneres do Paiz, idoneos ás leis federaes.

Tudo, pois, nos leva a esperar confiantes o almejado reconhecimento. Será talvez questão de tempo. E, de justiça, halde vir

Mas emiquanto não gosamos de semelihante regalia, por isto mesmo mais forte é o motivo para não consentirmos sejam esquecidas disposições protectoras firmadas por lei, que attenuam a demonstrada desegualdade.

Destas avulta a concedida pelo decreto n." 1.357 , de 19 de Dezembro de 1912, estabelecendo o curso da Esicola de Medicina e Cirurgia de S. Paulo, creado pela lei n. ${ }^{\circ} 19$ de 12 de Novembro de 1891.

No seu texto encontramos (4):

"Artigo 25 - Os formados pela Faculdade de Medicina e Cirurgia do Estado, que nella tenham feito todo o curso meddico-cirurgico, serão preferidos para nomeação de inspectores sanitarios, medicos de policia e outros cargos que demandem competencia profissional medica".

Pois bem. Contrariamente ao que era de se esperar, a esta lei não se tem dado o devido cumprimento. Não foi outro o motivo por que o Centro Academico “Oswaldo Cruz", elm feliz iniciativa, dirigiu ao Prof. dr. Edmundo Xavier o seguinte officio, assignado pelo doutorando Waldemar Barnsley Pessoa, seu esforçado presidente, e pelos demais companheiros de directoria:

"Eximo. Prof. Dr. Edmundo Xavier

O Centro Academico "Oswaldo Cruz", no intuto de zelar pelos interesses dos associados, que representa, vem pedir para assumpto de grande revelancia, a attenção do digno Director da Faculdade

(4) Lei promulgada pelo Cons. Rodrigues Alves, Presidente do Estadọ, sendc Secretario do Interior o dr. Altino Arantes. Publicada em $26-$ XII - 1912 . 
de Medicina e Cirurgia de São Paulo, como o mais autorisado poder que concorra para a satisfactoria solução de uma caso, em que actualmente se empenha a sociedadie.

O motivo que faz resaltar a opportunidade desta representação traz, pela analyse das Icircumstancias que o rodeiam, razões de justiça taes que certamente não hão de escapar ao esclarecido criterio de V. Exa.

De facto, Exmo. Sr. Director, quando da fundação dieste estabelecimento de ensino, tanto apoio mereceu do Governo a sua obra, que elle não se limitou a estabelecer as bases solidas da nova Faculdade e foi ao ponto de crear leis especiaes que protegessem todos aquelles. que por ella se formassem. E' assim que a mesma lei n. 1357 de 19 de Dezembro ide 1912 que determinou aquellas bases, incluio tambem em seus artigos uma disposição que visa especialmente os alumnos da nossa Faculdade, dando-lhes preferencia todas as vezes que entrem en: competição com medicos formados por outras escolas, na disputa de cargos estadoaes.

Nada mais̀ justo, é claro, porque a obra só se completaria definitivamente quando, modelada a sua organisação, todos os que a frenquentassem tivessem $o$ apoio forte de quem lhes abrira as portas do estabelecimento, onde viram coroados os seus esforços de seis longos. annos de estudo.

Todavia, embora sempre houvesse fundados motivos para que esta justa disposição foss a observada, vemos, agora que deviam es. plender as suas vantagens, que ella foi esquecida e com ella esquecidos os direitos daquelles para os quaes fora creada.

Não vae exaggero no que affirmamos. Ainda ha pouco, pretendendo um imedico recem-fformado pela nossa Escola occupar úm cargo em repartição estadoal, para cujo desempenhó the garantiam preferencia não só a supracitada lei como 16 mezes de serviço na mesma repartição e favor concedido por lei especial creada para os que trabalharam durante a pandemia de grippe, viu elle, com natural surpresa, postergados todos estes direitos, porque calcadas todas as disposições que o amparavam.

Não é preciso mais, Exmo. Sr., para que se evidencie a desvantajosa posição que se vae creando para todos os medicos formados pela nossa Faculdade - aquelles justamente que deveriam merecer do Governo o seu amparo seguro, não só porque alumnos de Faculdade estadoal senão tambem porque não lhes assistem regalias ccncedidas a outros medicos formados por estabelecimentos federaes.

Vemos assitm que os diplomados pela Faculdade de São Paulo, além de não poderem exercer sua profissão fóra do territorio que lhes marca o limite do Estado, ainda, no estreito ambito de sua acti- 
vidade, encontram obstaculos representados por direitos que lhes noga o mesmo Governo que os devia proteger.

Ficam dest'arte em inferioridede de condições, a que se junta o clamoroso desamparo da publica administração, os que, conhecendo o ensino desta Faculdade a ella preferiram certos de que, embora rão reconhecidos os seus diplomas pela União, tinham, além do bom aprendizado medico, as vantagens da protecção governamental do Estado.

Uige, pois, uma providencia salvadora; porque do contrario vamos caminhando para uma situação tal em que é evidente a injustiça que ameaça todos aquelles formados pela nossa Escola, cujas facilidades $\epsilon m$ vez de se augmentarem vão diminuindo, no meio em que labutam. Não é outro o motivo porque em hora feliz nos lembramos de recorrer a V. Fxa.

o prestigio dado pelas altas qualidades de V. Exa. ainda tem a augmental-o, no caso presente, o facto de ser V. Exa. Director desta Faculdade - isto é ter a direcção de todos os actos internos e a fiscalisação dos direitos que adquirem os que por ella se formarem.

Assim, quando já nos não falasse bastante o zelo de V Exa. pelas cousas que dizem respeito ao estabelecimento á sua guarda, o exito da causa presente teria por garantia principios innegaveis de justiça.

Tudo pois nos dá certeza de que alcançaremos o fim collimado. Para tanto confiamos em V. Exa. que, não desmentindo as fundadas esperanças dadas pela orientação intelligente que $V$ Exa. tem continuado na directoria da nossa Faculdade, ainda creará motivos maiores ao reconhecimento dos seus alumnos, defendendo a causa presente perante o Governo do Estado e pugnando para que sejam observadas as leis que protegem os formados por esta Escola.

Porque se estas leis attenuam os desfavores em que nos colloca - não reconhecimento federal da Escola, desapparecidas ou menos cresadas, será mesquinha a situação dos medicos paulistas, esquecidos do Gorerno e condemnados a exercer a profissão em acanhados limites.

V. Exa. porém, estamos certos, sraberá agir afim de que sejam poupados desrespeitos tão clamantes á JUSTIÇA!"

F. C. P. 